\title{
Classification of sags measured in a distribution substation using a fuzzy tool
}

\author{
J. Mora ${ }^{1}$, J. Meléndez ${ }^{1}$, J. Colomer ${ }^{1}$, D. Llanos ${ }^{1}$, J. Corbella ${ }^{2}$ and J. Sánchez ${ }^{2}$ \\ ${ }^{1}$ Control Engineering and Intelligent Systems Group - eXiT \\ University of Girona \\ Av. Lluis Santalo s/n. Building P.IV - Girona (Spain) \\ phone:+34 972 418391, fax:+34 972418 97601, e-mail: \{jjmora, quimel, colomer, dllanosr\}@eia.udg.es \\ ${ }^{2}$ ENDESA \\ FJCorbella@enher.es jslosada@fecsa.es
}

\begin{abstract}
This paper discuss about voltage sags classification using a previous characterization of this type of electrical disturbances. An automatic classification algorithm, working under a non-supervised strategy is proposed. The method helps to determine the possible fault cause and location of voltage sags using a prototype definition and the pertinence degree for each resulting class.
\end{abstract}

\section{Key words}

Classification, Learning machine, Faults, Power quality, Voltage sags.

\section{Introduction}

Recent power quality recommended practices establish world wide acceptable definitions to several quality indices. Monitoring methods and concerns about results interpretations are promoted by the increasing lost production, process downtime and damaged equipment. On the other hand, it is necessary to use the data available by electrical facilities to define strategies to improve the overall utility performance. The problem is to solve the interrogation proposed by the following question: What is the way to use the information provided by this methods to make a decision? [1].

According to the utility, it is necessary to take advantage of analysis performed on the amount of data collected over years of measurements. This data usually is related to electrical voltage and currents measures, gathered during power system events. It contains information about alteration of the sinusoidal wave parameters, transmitted through the electrical network. The article goal is to link such analysis with the incidences registered in databases by technicians and fault analysis engineers.

The responsibility of possible damages caused to customers is usually assigned to utilities [2]. Consequently the utilities are interested in monitoring (characterizing, recognizing and tracing causes and effects) of these perturbations as well as possible, to take remedial actions, instead of only saving data.

From artificial intelligence and data mining point of view, some techniques can help in this challenge. This paper discuss about a voltage sags classification previously characterized by rms filtering and symmetrical components techniques [3]-[4]. Significant sag features are used to give a description, useful for voltage sags classification and its association with causes and possible fault location. An automatic fuzzy classification algorithm, working under a non-supervised strategy is proposed to discover clusters of sags.

This paper is organized as follows: voltage sag characterization is presented in section 2. Temporal descriptors as magnitude, peaks, slopes and perturbation duration are proposed. Signal processing methods are used to obtain accurate information (filtering and symmetrical components) of the three-phase voltage signal. These descriptors characterize voltage sags instead of a pure waveform. In section 3, the fuzzy classification method and a numerical example are presented, while in section 4, the voltage sag classification and its analysis are performed to the individual or zone and transversal classifications approaches. A fuzzy learning machine tool is trained using the information extracted in section 2. In section 5, classes' prototypes are presented and registered faults are linked with its possible locations, by matching representative classes generated with a protection tree defined by the facility experts. Some examples of real voltage sags prototypes and its similitude degree are also presented and analysed in this section. Finally, some relevant conclusions and future work addresses are presented.

This approach is proposed as the starting point in case based strategy implementation for quality power management, taking into account that automatic classification of faults in power systems has not been widely treated and correct classification rates for the actual events are not as high as classification results used 
in areas such as pattern recognition, speech recognition, and so on [5]-[6].

Five steps are proposed to perform the voltage sag classification and its association to fault causes and possible location. Those steps are: waveform gathering, abstraction of significant sags descriptors, descriptors selection, sag classification and classes-cause final matching. This is schematically presented in Figure 1.

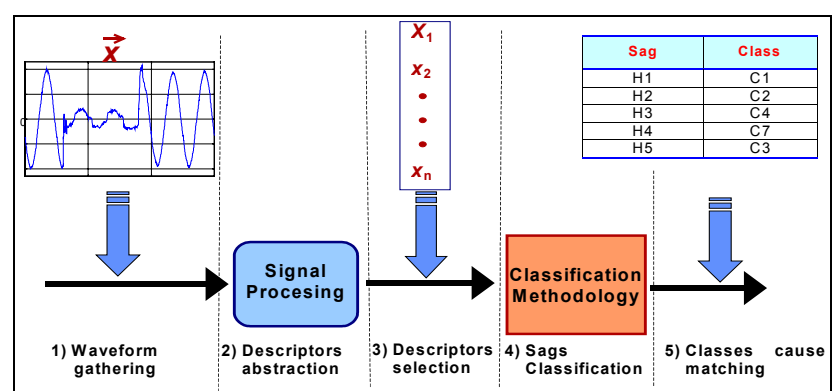

Figure 1. Functional steps for the identification process

Voltage sag waveforms were associated with supplementary information related to causes and fault location (transmission / distribution). According to the classification algorithm, these waveforms must be considered as objects characterized by a set of descriptors. Two types of temporal descriptors have been selected: three phase and single-phase ones, as presented in section 2 .

\section{Definition of Significant Voltage Sag Descriptors}

Basic quantitative voltage sag descriptors are obtained from recorded waveforms. Those are divided in threephase and single-phase descriptors [3].

\section{A. Three-phase Descriptors}

Three-phase descriptors were defined as it is presented in figure 2:

1) Three-phase sag magnitude $\left(h_{3 \varphi}\right)$ : Defined as the maximum drop of voltage of three-phase power system during the sag.

2) Three-phase sag duration $\left(d_{3 \varphi}\right)$ : Defined, as the maximum time during the rms voltage in a threephase power system, is lower to 0.9 p.u.

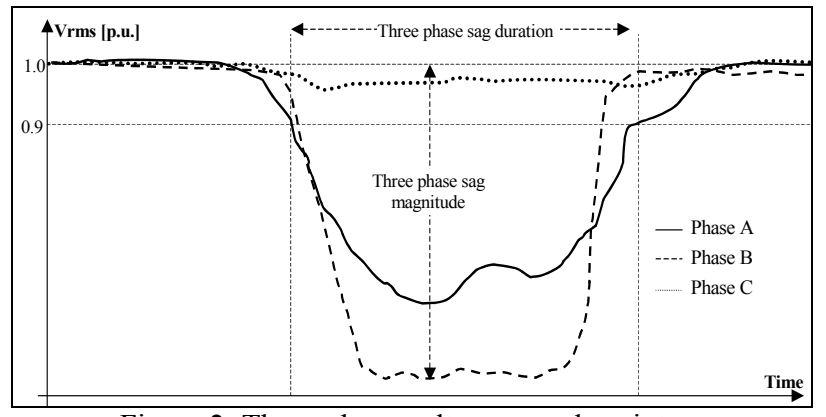

Figure 2: Three-phase voltage sags descriptors

\section{B. Single-phase Descriptors}

Single-phase descriptors were defined as showed in figure 3:

1) Single-phase sag magnitude $\left(h_{1 \varphi}\right)$ : Maximum voltage drops in every single phase of the power system.

2) Single-phase sag duration $\left(d_{l \varphi}\right)$ : Maximum time during the rms voltage is lower to 0.9 p.u. in every single phase of the power system .

3) Single-phase minimum stage duration $\left(\operatorname{msd}_{1 \varphi}\right)$ : Time during the rms voltage remains in an $\alpha$ width band over the minimum voltage value. In this case $\alpha$ was selected as $2 \%$.

4) Single-phase voltage fall slope $\left(v f s_{1 \varphi}\right)$ : Slope at the first part of the single-phase voltage sag. It is computed using the voltage magnitude diference beetween 0.9 and the $\alpha$ width band over the minimum voltage value.

5) Single-phase voltage recovery slope (vrs $\left.{ }_{1 \varphi}\right)$ : Slope in the last part of single-phase voltage sag. It is computed in the same way as the single-phase voltage fall slope is.

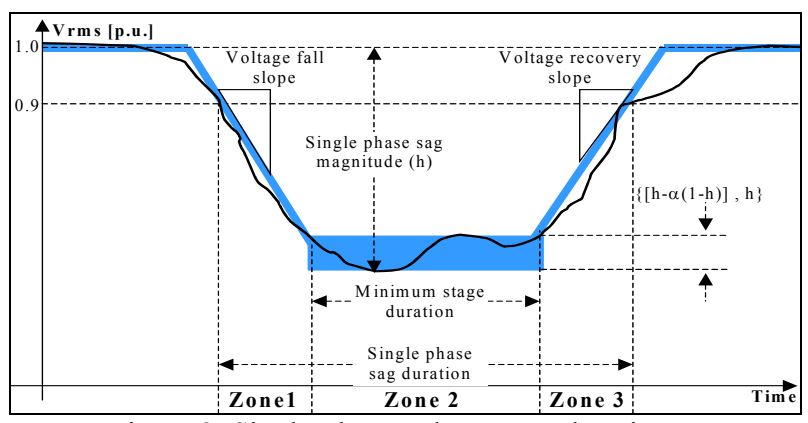

Figure 3: Single-phase voltage sags descriptors

\section{Temporal Zone Definition}

The temporal evolution of voltage sag presents three different zones according to different temporal fault stages (Figure 3).

1) Zone 1: It defines the starting stage of the fault, which produces the voltage sag. The selected descriptors are: Three-phase voltage sag magnitude, all single-phase voltage sag magnitudes, and voltage fall slope in each phase.

2) Zone 2: In this zone the fault is usually stabilized, and the protective relaying system is not causing any breaker trip to insolate the possible fault. The selected descriptors are: Three-phase voltage sag magnitude and duration, all single-phase voltage sag magnitude, all single-phase sag duration, and minimum stage duration for each phase.

3) Zone 3: In this zone, the protective relaying system opens the breaker to insolate the fault, as a consequence the voltage come back to its normal value (1.0 p.u. aprox.). The selected descriptors are: Three-phase voltage sag magnitude, all single-phase voltage sag magnitude and voltage recovery slope for each phase. 
Voltage sag classification obtained for zone 1 is directly related to fault type (single-phase to ground, three phase, and double-phase) and the probably to electrical distance (from the fault point to the point of voltage sag measurement). For zone 2 , the resulting groups should be related to the protective system relaying operation (It also depends on the location of these devices). Finally, zone 3 allows distinguishing among different types of loads (motors, transformers, etc). It provides information related to the utility customers.

\section{Fuzzy Classification Method}

\section{A. Method Description}

For classification purpose a Learning Algorithm for Multivariate Data Analysis-LAMDA has been used. This method combines both, numeric and symbolic classification algorithms, taking profit of fuzzy logic and hybrid connectives [7] [8]. This method is proposed as a classification technique to obtain voltage sags prototypes based on temporal descriptors [9]. The following paragraphs resumes the classification principle used in LAMDA.

One object X (sag) has a number of characteristics called "descriptors". These descriptors are used to describe the object (sag). Every object is assigned to a "class" in the classification process. Class $\left(\mathrm{k}_{\mathrm{i}}\right)$ is defined as the universe of descriptors, which characterize one set objects (sags) as presented in figure 4.

MAD (Marginal Adequacy Degree) concept is a term related to how similar is one object descriptor to the same descriptor of a given class, and GAD (Global Adequacy Degree) is defined as the pertinence degree of one object to a given class as in fuzzy membership functions $\left(\mathrm{m}_{\mathrm{ci}}(\mathrm{x})\right)[10]$.

Classification, in LAMDA, is performed according to similarity criteria computed in two stages. First MAD to each existing class is computed for each descriptor of an object. Second, these partial results are aggregated to get a GAD of an individual to a class [8]. The former implementation of LAMDA included a possibility function to estimate the descriptors distribution based on a "fuzzification" of the binomial probability function computed as (2). This approach was used in this work.

$$
\operatorname{MAD}\left(d_{i} x_{j} / \rho_{(i / k)}\right)=\rho_{(i / k)}^{d_{i} x_{j}}\left(1-\rho_{(i / k)}\right)^{\left(1-d_{i} x_{j}\right)}
$$

Where:

$$
\begin{aligned}
& d_{i} x_{j}=\text { Descriptor } \mathrm{i} \text { of the object } \mathrm{j} \\
& \rho_{(i / k)}=\text { Ro of descriptor } \mathrm{i} \text { and class } \mathrm{k}
\end{aligned}
$$

On the other hand, GAD computation was performed as an interpolation between a t-norm and a t-conorm by means of the $\beta$ parameter such that $\beta=1$ represents the intersection and $\beta=0$ means the union.

$$
G A D=\beta T(M A D)+(1-\beta) S(M A D)
$$

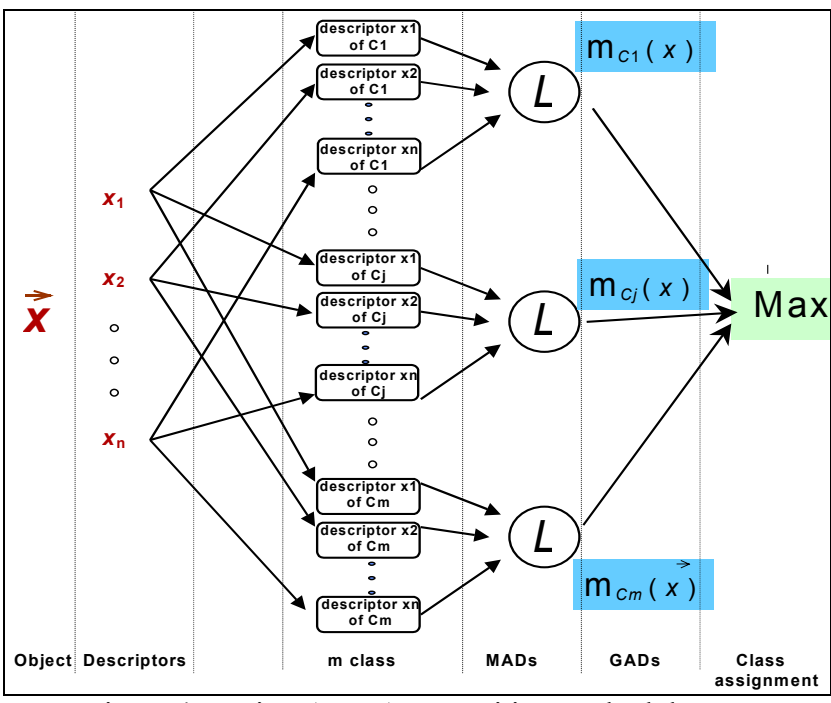

Figure 4: Basic LAMDA recognition methodology

\section{B. Classification numerical example}

This example shows how the classification method works on learning and recognition stages.

1) Training set: The training set is composed by five voltage sags or objects $X_{(\mathrm{n})}$. Every object $\mathrm{X}$ has three descriptors. These objects have been previously classified for an expert in two different classes according to the table 1. The Non Informative Class $-\mathrm{NIC}$ is determined as number 3

\begin{tabular}{|c|c|c|c|c|}
\hline \multirow{2}{*}{$\begin{array}{c}\text { Voltage } \\
\text { sag }\end{array}$} & \multicolumn{4}{|c|}{ Descriptor } \\
\cline { 2 - 5 } & $\begin{array}{c}\text { Recovery } \\
\text { slope }\left(v r s_{1 \varphi}\right)\end{array}$ & $\begin{array}{c}\text { Magnitude } \\
\left(h_{3 \varphi}\right)\end{array}$ & $\begin{array}{c}\text { Duration } \\
\left(d_{3 \varphi}\right)\end{array}$ & $\begin{array}{c}\text { Expert } \\
\text { Class }\end{array}$ \\
\hline $\mathrm{X}_{(1)}$ & 0,819 & 17,94 & 36,266 & $\mathbf{1}$ \\
\hline $\mathrm{X}_{(2)}$ & 0,165 & 14,066 & 66,28 & $\mathbf{1}$ \\
\hline $\mathrm{X}_{(3)}$ & 0,085 & 23,639 & 170,076 & $\mathbf{2}$ \\
\hline $\mathrm{X}_{(4)}$ & 2,363 & 36,592 & 239,795 & $\mathbf{2}$ \\
\hline $\mathrm{X}_{(5)}$ & 0,057 & 35,717 & 543,994 & $\mathbf{1}$ \\
\hline
\end{tabular}

Table 1: Voltage sag descriptors

2) Descriptors normalization: Some preliminary data conditioning is performer over the training data. Minimum and maximum values for each descriptor was determined and descriptor normalization is performed according to (4)

$$
X_{N}=\frac{X_{i}-X_{\min }}{X_{\text {máx }}-X_{\text {min }}}
$$

The normalized descriptors are presented in table 2 .

\begin{tabular}{|c|c|c|c|c|}
\hline \multirow{2}{*}{$\begin{array}{c}\text { Voltage } \\
\text { sag }\end{array}$} & \multicolumn{4}{|c|}{ Descriptor } \\
\cline { 2 - 5 } & $\begin{array}{c}\text { Recovery } \\
\text { slope }\left(v r s_{1 \varphi}\right)\end{array}$ & $\begin{array}{c}\text { Magnitude } \\
\left(h_{3 \varphi}\right)\end{array}$ & $\begin{array}{c}\text { Duration } \\
\left(d_{3 \emptyset}\right)\end{array}$ & $\begin{array}{c}\text { Expert } \\
\text { Class }\end{array}$ \\
\hline $\mathrm{X}_{(1)}$ & 0,330 & 0,172 & 0,000 & $\mathbf{1}$ \\
\hline $\mathrm{X}_{(2)}$ & 0,047 & 0,000 & 0,059 & $\mathbf{1}$ \\
\hline $\mathrm{X}_{(3)}$ & 0,012 & 0,425 & 0,264 & $\mathbf{2}$ \\
\hline $\mathrm{X}_{(4)}$ & 1,000 & 1,000 & 0,401 & $\mathbf{2}$ \\
\hline $\mathrm{X}_{(5)}$ & 0,000 & 0,961 & 1,000 & $\mathbf{1}$ \\
\hline
\end{tabular}

Table 2: Normalized voltage sag descriptors

The used $\mathrm{t}$-norma is minimun/maximun. 
3) Training procedure: During this procedure every learning parameter $\rho_{(\mathrm{i} / \mathrm{k})}$ is computed for each class $\boldsymbol{k}$ and descriptor $\boldsymbol{i}$. According to the training set, the number of elements in class one is three $(\mathrm{NEC}=3)$. Table 3 summarizes the calculation procedure.

\begin{tabular}{|c|c|c|}
\hline Class1-d1 & Class1-d2 & Class1-d3 \\
\hline$+0,330$ & $+0,172$ & $+0,000$ \\
$+0,047$ & $+0,000$ & $+0,059$ \\
$+0,000$ & $+0,961$ & $+1,000$ \\
\hline 0,377 & 1,133 & 1,059 \\
\hline$\rho_{(1 / 1)}=0,377 / 3=0,126$ & \\
$\rho_{(2 / 1)}=1,133 / 3=0,378$ & \\
$\rho_{(3 / 1)}=1,059 / 2=0,353$ & \\
\hline
\end{tabular}

Table 3: Learning parameter $\rho(\mathrm{i} / \mathrm{k})$ calculation

Performing the similar procedure to classes 2 and 3, the following results were obtained:

Clase 2:

$\rho_{(1 / 2)}=0,506 \quad \rho_{(2 / 2)}=0,712 \quad \rho_{(3 / 2)}=0,332$

Clase 3 (NIC):

$\rho_{(1 / 3)}=\rho_{(2 / 3)}=\rho_{(3 / 3)}=0,5$

4) Classification Process: To classify a new voltage sag $\mathrm{X}_{\mathrm{n}}$ denoted as $\mathrm{X}_{(6)}$ the following procedure was followed.

Normalization: New voltage object normalization was performed using (4). As a result, the following normalized sag descriptors classification is obtained as: $\mathrm{X}_{(6)}=\left[\begin{array}{lll}0.1 & 0.3 & 0.9\end{array}\right]$

MAD Calculation: The Marginal Adecuation Degree is computed as presented in (2). In this specific case, the MAD calculation is performed as follows:

$$
\operatorname{MAD}\left(d_{1} x_{6} / \rho_{11}\right)=0.126^{0.1}(1-0.126)^{(1-0.1)}
$$

GAD Calculation: The Global Adecuation Degree is computed as presented in (5)

$$
G A D\left(x_{j} / c_{k}\right)=\prod_{i=1}^{n d} M A D\left(d_{i} x_{j} / \rho_{i k}\right)
$$

Where:

$n d=$ Number of voltage sag descriptors

In this specific case, the GAD calculation is performed as follows:

$$
\begin{aligned}
& \operatorname{GAD}\left(x_{6} / c_{1}\right)=\prod_{i=1}^{3} \operatorname{MAD}\left(d_{i} x_{6} / \rho_{i 1}\right) \\
& \\
& \begin{array}{cccc}
\left(x_{6} / c_{1}\right) & \left(x_{6} / c_{2}\right) & \left(x_{6} / c_{\text {NIC }}\right) \\
\hline \text { GAD } & 0.054 & 0.126 & 0.123
\end{array}
\end{aligned}
$$

Highest adecuation degree verification: If recognition stage is performed, $\mathrm{X}_{6}$ corresponds to class $\mathrm{C} 2$, because it's greater GAD.
When learning is desired, then $\rho_{(\mathrm{i} / 2)}$ is updated. This option is chosen to reinforce the classification tool initial learning process. The $\rho$ update is performed by using (6)

$$
\rho\left(d_{i} / c_{k}\right)_{\text {new }}=\rho\left(d_{i} / c_{k}\right)_{\text {old }}+\frac{1}{N E C+1}\left[d_{i} x_{\text {new }}-\rho\left(d_{i} / c_{k}\right)_{\text {old }}\right](6)
$$

In the particular case of this example, the following update procedure is performed:

\begin{tabular}{l|lll} 
& $\left(d_{1} / c_{2}\right)$ & $\left(d_{2} / c_{2}\right)$ & $\left(d_{3} / c_{2}\right)$ \\
\hline$\rho$ & 0.371 & 0.575 & 0.521
\end{tabular}

When the maximum adecuation degree corresponds to the NIC class, then a new class is created.

\begin{tabular}{c|ccc} 
& $\left(d_{1} / c_{N I C}\right)$ & $\left(d_{2} / c_{N I C}\right)$ & $\left(d_{3} / c_{N I C}\right)$ \\
\hline$\rho$ & 0.367 & 0.433 & 0.633
\end{tabular}

Now, the NIC class corresponds to class 4 .

\section{Classification Results and Analysis}

The classification is performed based on temporal descriptors of voltage sags as presented in section 2 . The proposed analysis considers the individual behaviour of the classification in every zone (individual analysis) and the behaviour of groups of sags according to the conjunction of the three zones (transversal or sag analysis). Using this classification results, some relations between location and sag cause is developed in the following section.

\section{Individual (or zone) analysis}

The presence of each individual class for data in transmission or distribution systems and its percentage rate, are determined. The total amount of data of voltage sags corresponds to 38 voltage sags $(70.37 \%)$ caused by faults in transmission systems and 16 voltage sags $(29.62$ $\%$ ) caused by faults in distribution systems, all of these measured in the same distribution substation. Table 4 summarizes the obtained results [3].

According to this analysis, it is possible to identify classes that only appear in transmission or in distribution system. It is useful to identify the possible fault location, using only this type of analysis.

In addition for each class exist a prototype, which characterize this cluster. It is obtained from the learning parameter for the respective class and for every descriptor, defined for each classification zone according to the proposed in numeral 2, literal $\mathrm{C}$. The resulting prototype defines the respective class characteristics. Some real prototypes are presented in table 6 and figures $7 \mathrm{~A}$ to $7 \mathrm{~F}$. 


\begin{tabular}{|c|c|c|c|c|c|c|}
\hline \multirow{2}{*}{$\begin{array}{c}\text { Voltage } \\
\text { level }\end{array}$} & \multicolumn{2}{|c|}{ Zone 1} & \multicolumn{2}{|c|}{ Zone 2} & \multicolumn{2}{|c|}{ Zone 3} \\
\hline & Yes & Not & Yes & Not & Yes & Not \\
\hline 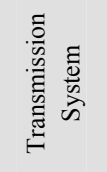 & $\begin{array}{l}\mathbf{1}(18.5 \%) \\
\mathbf{2}(22.2 \%) \\
\mathbf{3}(18.5 \%) \\
\mathbf{5}(9.26 \%)\end{array}$ & 4 & $\begin{array}{c}\mathbf{1}(13 \%) \\
\mathbf{4}(1.85 \%) \\
\mathbf{2}(37 \%) \\
\mathbf{5}(3.7 \%) \\
\mathbf{3}(13 \%)\end{array}$ & 6 & $\begin{array}{l}\mathbf{1}(27.8 \%) \\
\mathbf{5}(1.85 \%) \\
\mathbf{3}(16.7 \%) \\
\mathbf{4}(20.4 \%)\end{array}$ & \\
\hline 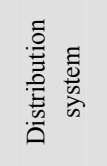 & $\begin{array}{l}\mathbf{3}(1.85 \%) \\
\mathbf{5}(9.26 \%) \\
\mathbf{4}(20.4 \%)\end{array}$ & $\begin{array}{l}1 \\
2\end{array}$ & $\begin{array}{c}\mathbf{1}(13 \%) \\
\mathbf{5}(5.56 \%) \\
\mathbf{2}(1.85) \\
\mathbf{6}(3.7 \%) \\
\mathbf{3}(7.41 \%)\end{array}$ & 4 & $\begin{array}{l}\mathbf{3}(24.1 \%) \\
\mathbf{4}(5.56 \%) \\
\mathbf{5}(1.85 \%)\end{array}$ & 1 \\
\hline
\end{tabular}

Table 4: Resulting classes in the individual analysis for voltage sags in transmission and distribution systems

\section{Transversal (or sag) analysis}

This analysis considers the whole perturbation (sag) as a sequence of classes (obtained from every individual zone), e.g. class " 123 " means class 1 in the first zone, class 2 in the second zone and class 3 in the third one.

Taking into account the results of this analysis, it is possible to determine which combination of classes are representatives to define the possible fault location and to classify fault origin as transmission or distribution systems as well [3]. This deep analysis is presented in the next section.

\section{Fault Diagnosis Approach}

\section{A. Fault Location Scheme}

The electric facility's engineers provided the fault location scheme depicted in figure 5 was proposed. It has been used to locate and establish the relationship between classes and voltages sags. As a consequence of faults, the protective relaying system sends the signal trip to one or more breakers, which starts the fault recovery zone (zone 3) of voltage sags. The time delay between the beginning of the fault and the relay actuation has been used to better identify or to locate faults.

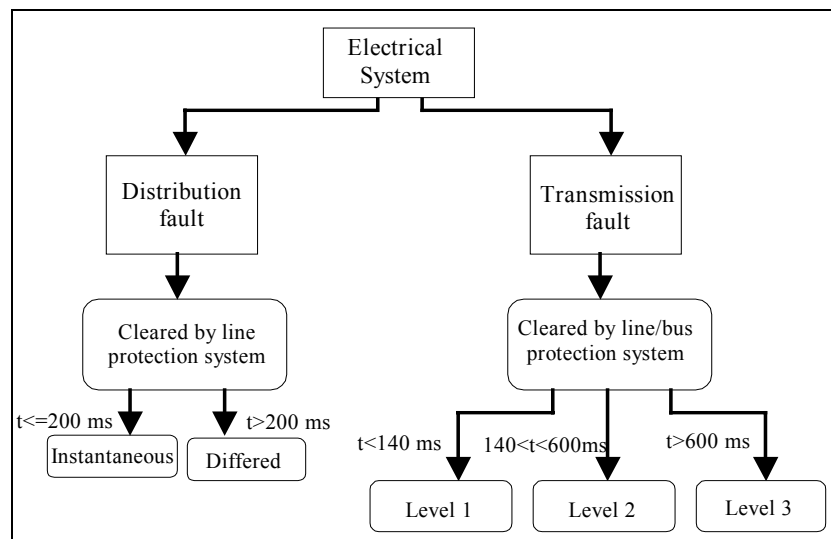

Figure 5: Fault location scheme

The times showed in figure 5 include the protective system delay and the breaker interrupting time (3-5 cycles). This time has been used as reference to the voltage sag duration.

\section{B. Voltage Sags Class and Fault Location Scheme}

In figure 6 the relation between the fault location scheme provided by the facility's experts and the classification results is presented. According to this figure, it is possible to determine some characteristic class associated to the previous defined line level actuations (1, 2 and 3). In addition, there are some classes strongly related to the characterized states for distribution lines (differed and instantaneous).

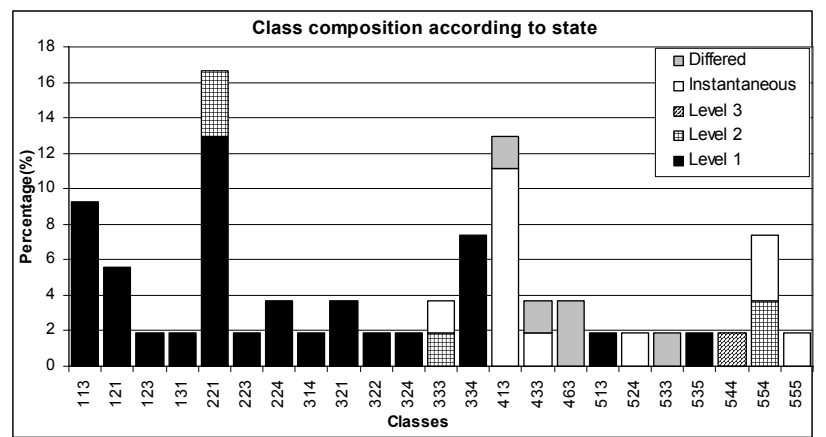

Figure 6: Voltage sags class composition according to proposed fault location scheme

The characteristic classes associated to level 1 are the predominant ones, and these are directly associated to the transmission system. In the same way, the classes related to the instantaneous state are the predominant ones and these are related to the distribution system.

On the other hand, the classes $1 \mathrm{xx}, 2 \mathrm{xx}$ and $3 \mathrm{xx}$ are strongly relate to transmission systems (levels 1 and 2), whereas the classes $4 \times x$ are related to distribution systems (differed and instantaneous). This classification helps to locate the fault by simple association with class.

\section{Class Prototypes}

Using the transversal or sag analysis, the characteristic prototypes of all possible classes were determined ( $Z 1$, $\mathrm{Z2}$ and Z3). The possible classes are due to the combination of the resulting classes for the zone analysis. In the specific case of the distribution substation analysed appear 23 classes from set of 150 possible transversal classes. Exist real voltage sag by every class prototype. This sag, called "real prototype", is obtained as the sag $\boldsymbol{j}$, which has the maximum similitude degree-MSD, to the class prototype $\boldsymbol{k}$. This similitude degree SD, is obtained using (7).

$$
S D_{j, k}=1-\sum_{i=1}^{n d}\left|\left(d_{i} x_{j}\right)_{\text {real j }}-\left(d_{i} x_{j}\right)_{\text {prototype }}\right|
$$

The MSD is obtained as proposed in (8)

$$
M S D_{k}=\max \left(S D_{1, k}, S D_{2, k}, \ldots, S D_{N, k}\right)
$$

Where $\mathrm{N}$ is the total number of real sags compared to the prototype $\boldsymbol{k}$.

Using this real prototype is possible to deduce what are the possible causes and the location of a new voltage sag, recognized as a member of some defined class. In 
addition, due the fuzzy nature of the proposed method, several possible solutions with a pertinence degree are also proposed. As example, a new sag is gathered to be classified by its possible causes and fault location determination. The results of the classification are presented in table 5 .

\begin{tabular}{|c|c|c|c|c|c|c|}
\hline & \multicolumn{6}{|c|}{ Class prototype } \\
\cline { 2 - 7 } & $\mathbf{1 1 3}$ & $\mathbf{2 2 4}$ & $\mathbf{3 2 4}$ & $\mathbf{3 3 3}$ & $\mathbf{4 6 3}$ & $\mathbf{5 4 4}$ \\
\hline $\begin{array}{c}\text { Pertinence } \\
\text { degree }\end{array}$ & 0.89 & 0.61 & 0.58 & 0.21 & 0.26 & 0.16 \\
\hline
\end{tabular}

Table 5: Certainty degree in voltage sag recognition stage

According to table 5, the voltage sag is classified as 113 (0.89), however is possible to associate this causes and possible fault location to the associate ones at $224(0.61)$ and $324(0.58)$ prototypes. The pertinence degree to prototypes 333, 463 and 544 is insufficient to be taken into account. As a conclusion, this voltage sag is a originated in the transmission system, and it is located into level 1 of the protection area (generally, into $80 \%$ line length).

Although the new sag is compared to all prototypes, in table 5 only is presented the meaningful ones for this example analysis.

In table 6 some examples of real prototypes are presented. This table presents all the voltage sags descriptors considered in the classification processes. The zero value means not voltage sag in this phase. The voltage sag prototypes rms plots are depicted in figures $7 \mathrm{~A}$ to $7 \mathrm{~F}$.

In subplot 7A, the real prototype of class 113 is presented. According to figures 5 and 6 , it corresponds to voltage sag originated in the transmission system, on level 1. This sags is characterized by its short duration (due to the response of protective system in transmission level) and nonrectangular shape.

In figure $7 \mathrm{~B}$, the real prototype of class 221 is depicted. It corresponds to a voltage sag originated in the transmission system, on level 1 or 2 . Sag duration is longest than class 113 duration, and for this reason this prototype represent characteristics of level 1 and 2 corresponding to zone 1 or 2 of line distance relay.

The real prototype of class 544 is presented in figure 7F. It presents a voltage sag originated in transmission system and removed possibly by the zone 3 of line distance relay.

In figures $7 \mathrm{C}$ and $7 \mathrm{E}$, the real class prototypes for classes 413 and 524 respectively are depicted. It represents voltage sags originated in a distribution substation by fault produced in local distribution system. According to figures 5 and 6 , this voltage sags classes are characterized as distribution cleared by instantaneous protection.

Finally, in figure 7D, the real class prototype corresponding to voltage sags originated on local distribution systems, removed by differed actuation of the protection system is presented.

\section{Conclusions}

A fuzzy classification tool has been used to relate voltage sags records to its possible cause and location. Voltage sag prototypes by the resulting classes are also given. Using the proposed classification approach, some classes strongly related to one real situation defined by the facility's experts have been determined. Determination of location and possible cause of new voltage sag has been performed, addressing the restoration plan and prevent some types of events in the future.

\section{Future Work}

As a future work and having enough amounts of data, it will be possible to consider faults in power transformer, power breakers and devices located on final customers facilities. In this way, the real prototypes defined and fault scheme proposed will be reflect the real power system. This goal will be accomplished by using ENSESA's voltage sag database of the region of Catalunya-Spain.

\section{Acknowledgments}

This work has been partially supported by Spanish government and FEDER funds (SECSE, DPI2001-2198) and a contract between UdG and ENDESA Distribution.

The authors want to thank the contribution of GISEL group of Universidad Industrial de Santander (Colombia), for the support related to power engineering knowledge.

\section{References}

[1] A. McEachern, "Roles of Intelligent Systems in Power Quality Monitoring: Past Present and Future", Proceedings IEEE Summer meeting 2001. Vol 3 pp1103-1105.

[2] M.H.J. Bollen, "Understanding Power Quality problems" IEEE Press. New York, 2000.

[3] J. J. Mora, D. Llanos, J. Meléndez, J Colomer, J Corbella, J. Sánchez, "Classification of Sags Measured in a Distribution Substation based on Qualitative and Temporal Descriptors", Proceedings CIRED 2003.

[4] D. Llanos, J. Meléndez, J. Colomer, J. Mora, J Corbella, J. Sánchez, "Abstraction of significat tempopral features of voltaje sags recorded in a $25 \mathrm{kV}$ substation" Procedings ICREP 2003.

[5] L.I. Eguiluz, M Manana; J.C. Lavandero, "Disturbance classification based on the geometrical properties of signal phase-space representation". Proceedings International Conference on Power System Technology 2000, Vol 3.

[6] M. Kezunovic, "Automated analysis of voltage sags, their causes and impacts". Power Engineering Society Summer Meeting, 2001, Volume: 2. 
[7] K. Moore, "Using neural nets to analyse qualitative data". A Marketing Research, 1995, vol. 7, nº 1, p.35-39.

[8] J. Aguilar-Martin and R. López de Mántaras,1982, "The process of classification and learning the meaning of linguistic descriptors of concepts". Approximate Reasoning in Decision Analysis,1982. p. 165-175. North Holland.
[9] N. Piera, "Connectius de logiques no estandard com a operadors d'agregació en classificació multivariable $i$ reconeixement de formes" Doctorate dissertation in the Universitat Politècnica de Catalunya, 1987.

[10] J.C Aguado, "A Mixed Qualitative-Quantitative SelfLearning Classification Technique Applied to Situation Assessment in Industrial Process Control". Ph. D. Thesis Universitat Politècnica de Catalunya, 1998.

\begin{tabular}{|c|c|c|c|c|c|c|c|c|c|c|c|c|c|c|c|c|c|c|c|}
\hline \multirow{2}{*}{$\begin{array}{l}\text { Voltage Sag } \\
\text { Identification }\end{array}$} & \multirow{2}{*}{$d_{3 \varphi}$} & \multirow{2}{*}{$\mathbf{h}_{3 \varphi}$} & \multicolumn{5}{|c|}{ Phase 1} & \multicolumn{5}{|c|}{ Phase 2} & \multicolumn{5}{|c|}{ Phase 3} & \multirow{2}{*}{ Class } & \multirow{2}{*}{ MSD } \\
\hline & & & $h_{1 \varphi}$ & $d_{1 \varphi}$ & $v f s_{1 \varphi}$ & $\operatorname{msd}_{1 \varphi}$ & $v r s_{1 \varphi}$ & $h_{1 \varphi}$ & $d_{1 \varphi}$ & $v f_{1 \varphi}$ & $\operatorname{msd}_{1 \varphi}$ & $v r s_{1 \varphi}$ & $h_{1 \varphi}$ & $d_{1 \varphi}$ & $v f s_{1 \varphi}$ & $\operatorname{msd}_{1 \varphi}$ & $v r s_{1 \varphi}$ & & \\
\hline S240202 02_35_36 & 36.266 & 17.940 & 0.000 & 0.000 & 0.000 & 0.000 & 0.000 & 17.940 & 36.266 & 0.454 & 9.067 & 0.819 & 0.000 & 0.000 & 0.000 & 0.000 & 0.000 & 113 & 0.929 \\
\hline S140302 15_22_32. & 170.076 & 23.639 & 0.000 & 0.000 & 0.000 & 0.000 & 0.000 & 23.639 & 170.076 & 1.407 & 0.625 & 0.085 & 10.969 & 149.442 & 0.025 & 63.466 & 0.020 & 413 & 0.903 \\
\hline S300402 14_11_50 & 239.795 & 36.592 & 0.000 & 0.000 & 0.000 & 0.000 & 0.000 & 36.592 & 239.795 & 2.363 & 217.285 & 2.363 & 14.639 & 227.289 & 0.028 & 52.211 & 0.593 & 463 & 0.807 \\
\hline S040502 15_57_33 & $\mid 184.458$ & 23.490 & 23.490 & 184.458 & 1.348 & 0.000 & 0.077 & 0.000 & 0.000 & 0.000 & 0.000 & 0.000 & 0.000 & 0.000 & 0.000 & 0.000 & 0.000 & 524 & 0.924 \\
\hline S220802 05_38_01 & 547.433 & 37.552 & 37.552 & 547.433 & 0.464 & 28.450 & 0.060 & 35.717 & 543.994 & 0.413 & 27.200 & 0.057 & 36.163 & 540.555 & 0.427 & 457.080 & 1.179 & 544 & 0.801 \\
\hline
\end{tabular}

Table 6: Real prototypes descriptors
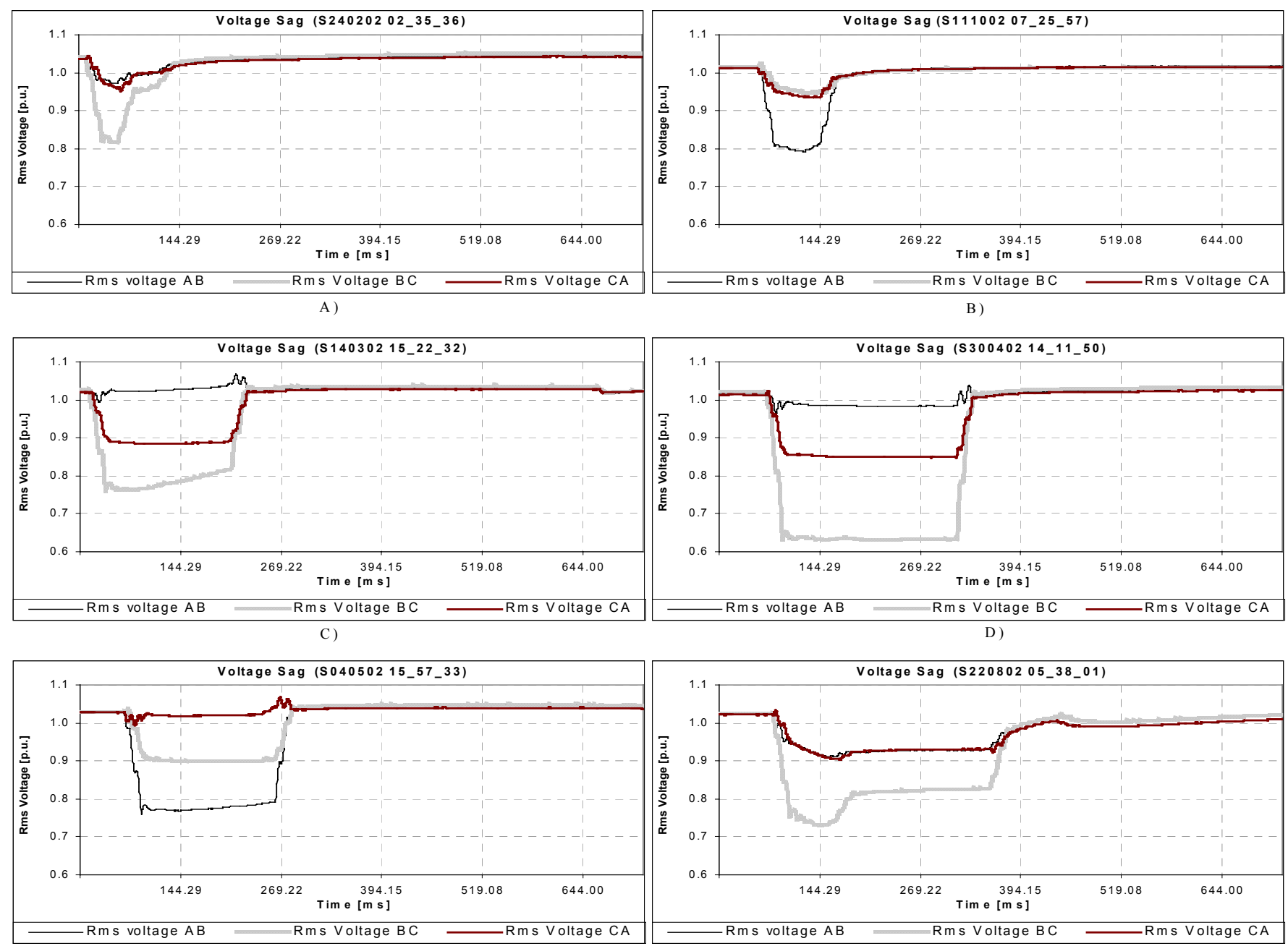

Figure 7: Voltaje sags prototypes 